\title{
Cognitive insight is associated with perceived body weight in overweight and obese adults
}

Sharain Suliman * D, Leigh L. van den Heuvel, Sanja Kilian, Erine Bröcker, Laila Asmal, Robin Emsley and Soraya Seedat

\begin{abstract}
Background: Accurate perception of body weight is necessary for individuals with a high body mass index (BMI) to initiate strategies to improve their health status. Furthermore, identifying factors that influence accurate body weight perception can assist in designing appropriate educational and weight management programs. We therefore aimed to investigate whether levels of cognitive functioning and insight influence the ability to correctly judge body weight.

Methods: One hundred and eighty four overweight and obese adults who participated in a cross- sectional casecontrol study and were controls in the aforementioned study were included. The study was conducted in Cape Town, South Africa. Demographic, weight-related, neuropsychiatric, neurocognitive and cognitive insight measures were administered. Regression analysis was conducted to determine the factors associated with correct weight perception.

Results: The final regression model explained $52.3 \%$ of variation in accurate perception of body weight and was significant $(p \leq 0.001)$. The model correctly classified $79.3 \%$ of individuals who were able to correctly and incorrectly judge their weight. Adults with higher BMI, and lower self-certainty, those who reported that they had gained weight in the previous year and those who were told by a healthcare professional to lose or maintain a healthy weight were more likely to correctly judge their weight.

(Continued on next page)
\end{abstract}

\footnotetext{
* Correspondence: sharain@sun.ac.za

Department of Psychiatry \& MRC Genomics of Brain Disorders Unit,

Stellenbosch University, PO Box 241, Cape Town 8000, South Africa
}

(c) The Author(s). 2021 Open Access This article is licensed under a Creative Commons Attribution 4.0 International License, which permits use, sharing, adaptation, distribution and reproduction in any medium or format, as long as you give appropriate credit to the original author(s) and the source, provide a link to the Creative Commons licence, and indicate if changes were made. The images or other third party material in this article are included in the article's Creative Commons licence, unless indicated otherwise in a credit line to the material. If material is not included in the article's Creative Commons licence and your intended use is not permitted by statutory regulation or exceeds the permitted use, you will need to obtain permission directly from the copyright holder. To view a copy of this licence, visit http://creativecommons.org/licenses/by/4.0/ The Creative Commons Public Domain Dedication waiver (http://creativecommons.org/publicdomain/zero/1.0/) applies to the data made available in this article, unless otherwise stated in a credit line to the data. 


\begin{abstract}
(Continued from previous page)
Conclusion: Some aspects of cognitive insight (self-certainty) but not cognitive functioning were associated with perception of body weight in this sample. Awareness of recent weight changes, higher BMI and advice from of health care professionals were also significantly associated with perception of body weight, while demographic variables were not. Understanding the factors that contribute to the correct perception of weight is important in identifying appropriate health interventions that may address the burden of associated non-communicable diseases in overweight and obese individuals.
\end{abstract}

Keywords: Cognitive insight, Cognitive function, Neurocognition, Weight perception

\section{Background}

Overweight and obesity are risk factors for numerous health problems, including cardiovascular disease, diabetes, hypertension, high cholesterol, musculoskeletal disorders and some forms of cancer [1,2]. Obesity is associated with a higher risk of chronic illness and consequently significant additional health care costs $[1,2]$. Increasing rates of obesity are, therefore, a public health concern worldwide, and particularly in many low- and middle-income countries (LMIC) where, in addition to the ongoing problems of infectious diseases and undernutrition, there is also a rapid increase in noncommunicable disease risk factors such as overweight and obesity [2]. This has been referred to as the 'double burden of malnutrition' [3].

Perceived body weight (PBW) is the personal evaluation of one's weight as "underweight", "normal weight" or "overweight" irrespective of actual Body Mass Index (BMI) [4-6]. Some individuals incorrectly judge their own body weight, with overweight individuals tending to underestimate their body size and underweight individuals tending to overestimate their body size. In the South African National Health and Nutrition Examination Survey, $84.5 \%$ of participants had a distorted perception of their weight [7].

Several studies have documented an association between incorrect perception of weight and mental health problems. Cross-sectional studies have reported associations with psychological distress, depression, and suicidal ideation, and even work absenteeism [8-12]. A longitudinal study conducted in Australia similarly found that the perception of being overweight during adolescence was a significant risk factor for later depression in young adult men and women [13]. In contrast, other studies have reported protective effects of weight misperception. A longitudinal study found that weight misperception among overweight/obese adolescents of white ethnicity in the USA may be protective against depression in adulthood [14]. Other cross-sectional studies have also found a protective effect of misperceived weight on mental health $[15,16]$.

Accurate perception of body weight is influenced by a number of factors, many of which affect actual weight, including age, gender, family, societal values, ethnicity, education level and socio-economic status (SES) [4, 1721]. Cognitive functioning, particularly executive functioning, has also been linked to excess weight [22-25] as well as to accurate perception of body weight [26]. Cognitive insight, a process of self-evaluation that considers both an individual's ability and willingness to objectively reflect on their beliefs, and their certainty that these beliefs are correct, is believed to be associated with cognitive functioning [27-29]. Previous studies suggest that poor cognitive insight is associated with impaired episodic memory [30] and executive functioning [31]. PBW may thus be influenced by cognitive functioning and insight.

To our knowledge, there has been no study evaluating the relative contributions of cognitive functions and $\operatorname{cog}$ nitive insight on PBW. Identifying factors that influence or predict poor body weight perception can assist in designing more appropriate educational and weight management programs. In this study we investigated PBW with a particular focus on underestimating weight in a cohort of South African adults to determine the prevalence as well as the cognitive and socio-demographic correlates of accurate perception of weight. We further investigated the association between cognitive performance and insight and the ability to correctly judge body weight. Specifically, we asked "Does cognitive functioning influence PBW?", "Does cognitive insight play a role in PBW?", and "Which socio-demographic features influence PBW?" Individuals with abnormal weight who do not accurately perceive their own body weight may be less likely to initiate strategies to improve their health status, further highlighting the need to better understand the determinants of overweight/ underweight in LMICs and in ethnically diverse populations $[17,18]$. This research adds to the scarce literature on the relationship between cognition and weight perception, particularly in LMICs and non-Caucasian populations.

We hypothesised that (i) better cognitive functioning would be associated with improved accuracy of PBW; (ii) better cognitive insight (higher self-reflectiveness, i.e. objectivity and reflectiveness) and lower self-certainty (i.e. overconfidence in own beliefs) would be associated 
with correct PBW; and (iii) socio-demographic factors such as age, gender, education level, and income would influence PBW.

\section{Methods}

Participants

Participants were selected from $N=314$ mixed-race adults (aged $\geq 18$ years), recruited as non-psychiatric controls for a cross-sectional, case-control project titled "Understanding the SHARED ROOTS of Neuropsychiatric Disorders and Modifiable Risk Factors for Cardiovascular Disease study". Participants were recruited through community newspaper advertisements and fliers. The study was approved by the Stellenbosch University Faculty of Medicine and Health Sciences Human Research Ethics Committee (reference number: N13/08/ 115), conducted in accordance with the Declaration of Helsinki, and all participants signed informed consent. Participants were excluded if they were unable to read, write and understand the Informed Consent documents in English or Afrikaans, diagnosed with a major medical illness (e.g., epilepsy, cancer, HIV, stroke), or psychiatric disorder (e.g. schizophrenia, other psychotic disorder, bipolar disorder, substance use disorder, anxiety or depressive disorder) or neurological disorder, had experienced a head injury with loss of consciousness, were on psychiatric medication, or pregnant.

\section{Measures}

Neuropsychiatric and neurocognitive measures were administered by clinicians and researchers trained in their use and in the participants' language of choice (English or Afrikaans). Appropriate cultural and language adaptations were made to the neurocognitive tests and test instructions with stimuli and response booklets translated into Afrikaans and back-translated into English by independent translators [32, 33] (Personal communication with Dr. Randolph, 2014). Reliability (Cronbach's alpha) was in the acceptable range $(0.7-0.8)$ for all instruments.

- A demographic questionnaire included sociodemographic factors (age, gender, years of education, income, marital status), and past and current medical and psychiatric history.

- The MINI International Neuropsychiatric Interview (MINI- version 6) was used to assess for major psychiatric disorders, including Major Depressive Episode. The MINI has been shown to have high validity and reliability scores when compared with results from the Structured Clinical Interview for DSM-III-R, the Composite International Diagnostic Interview, the Diagnostic Interview Schedule and the Present Status Examination [34]. Participants who screened positive for any disorder were excluded from the analysis.

- Height $(\mathrm{cm})$ and body weight $(\mathrm{kg})$ were objectively measured by study nurses. Weight status was subsequently determined according to standardized body mass index (BMI) classification: $<18.5-$ underweight; 18.5-24.9 - normal; 25-29.9 overweight; 30-34.9 - obese class I; 35.0-39.9 obese class II; > 40.0 - obese class III [35].

- Current weight perception was based on a selfreport question -where individuals were asked to estimate their own weight according to three categories (underweight, normal weight, overweight). Individuals were stratified according to whether they correctly or incorrectly perceived their current body weight status and whether they underestimated or overestimated their weight status.

- Other weight-related information from the World Health Organisation STEPS questionnaire [36] included waist circumference, family history of obesity, weight changes in the last 12 months, and receipt of weight advice from a health-care professional.

- The Beck Cognitive Insight Scale (BCIS), a commonly used and well-validated measure of cognitive insight, was used to assess for objectivity and reflectiveness (higher $=$ better insight) and selfcertainty (lower/ less confidence in own beliefs = better insight) [27]

- The Wechsler Abbreviated Scale of Intelligence (WASI) was used to estimate global IQ [37], (to potentially include as covariate).

- The Repeatable Battery for the Assessment of Neuropsychological Status (RBANS), assessed immediate and delayed memory, attention, language, and visuospatial skills [38]. The following tests of Executive Functioning were also administered: The Ruff Figural Fluency Test [39], Stroop colour word test [40], Digit span and Spatial span / Corsi blocks [41] . An estimate of overall cognitive ability was computed by creating z-scores for each RBANS and executive functioning test, which were then added up to create a total neurocognition score.

\section{Statistical analyses}

Chi-square $\left(x^{2}\right)$ tests were used to determine which categorical variables were associated with $\mathrm{PBW}$ and ANOVA or Mann-Whitney U tests, as appropriate, were run to determine the continuous variables that were associated with PBW. Significant factors from univariate analyses were entered into a stepwise logistic regression models to identify the factors that were significantly associated with accurate PBW. IBM SPSS version 26 was used to analyse the data with a 2-sided significance level set at 0.05 . 
Table 1 Demographic, Weight and Neurocognitive Variables for Full and Included Samples

\begin{tabular}{|c|c|c|}
\hline & Full sample: $N=314$ & Included sample: $N=184$ \\
\hline Variable & N (Percentage) & N (Percentage) \\
\hline \multirow[t]{2}{*}{ Gender } & Male: 97 (30.9) & Male: 47 (25.5) \\
\hline & Female: 217 (69.1) & Female: 137 (74.5) \\
\hline \multirow[t]{3}{*}{ **Education (highest level completed) } & < Primary school: 28 (8.9) & < Primary school: 20 (10.9) \\
\hline & Some Secondary School: 163 (51.9) & Some Secondary School: 100 (54.3) \\
\hline & Completed Secondary School: 123 (39.2) & Completed Secondary School: 64 (34.8) \\
\hline \multirow[t]{4}{*}{ Marital Status \# } & Married/ Cohabitating: 138 (43.9) & Married/ Cohabitating: 52 (28.3) \\
\hline & Never Married: 119 (37.9) & Never Married: 98 (53.3) \\
\hline & Divorced/ Separated/ & Divorced/Separated/ \\
\hline & Widowed: 57 (18.2) & Widowed: 34 (18.5) \\
\hline \multirow[t]{2}{*}{ Employment } & Yes: 122 (38.9) & Yes: 63 (48.2) \\
\hline & No: 192 (61.1) & No: 121 (65.8) \\
\hline \multirow[t]{5}{*}{ Monthly Income } & < R1500: 46 (14.6) & < R1500: 24 (13.6) \\
\hline & R1500 - R3000: 86 (27.4) & R1500 - R3000: 54 (30.5) \\
\hline & R3000 - R6000: 77 (24.5) & R 3000 - R6000: 49 (27.7) \\
\hline & R6000 - R12000: 49 (15.6) & R6000 - R12000: 24 (13.6) \\
\hline & > R12000: 41 (13.1) & > R12000: 26 (14.7) \\
\hline \multirow[t]{2}{*}{ Weight Perceived Correctly } & Yes: 209 (66.6) & NA \\
\hline & No: 105 (33.4) & \\
\hline \multirow[t]{2}{*}{ Underestimated Weight } & Yes: 92 (29.3) & NA \\
\hline & No: 222 (70.7) & \\
\hline \multirow[t]{2}{*}{ Overestimated Weight } & Yes: $13(4.1)$ & NA \\
\hline & No: 301 (95.9) & \\
\hline \multirow[t]{2}{*}{${ }^{* *}$ Ever overweight/ obese } & Yes: $141(44.9)$ & Yes: 105 (57.1) \\
\hline & No: 173 (55.1) & No: 79 (42.9) \\
\hline \multirow[t]{3}{*}{${ }^{* *}$ Weight changes in previous year } & Yes - weight increased: 69 (22) & Yes - weight increased: 49 (26.6) \\
\hline & Yes - weight decreased: 45 (14.3) & Yes - weight decreased: 24 (13.0) \\
\hline & No: 200 (63.7) & No: 111 (60.3) \\
\hline \multirow[t]{2}{*}{ **Family member overweight } & Yes: $118(37.6)$ & Yes: 76 (41.3) \\
\hline & No: 190 (60.5) & No: 108 (58.7) \\
\hline \multirow[t]{2}{*}{ **Told to maintain healthy weight by health-care professional } & Yes: 119 (37.9) & Yes: 77 (41.8) \\
\hline & No: 195 (62.1) & No: 107 (58.2) \\
\hline
\end{tabular}

\section{Variable}

${ }^{*}$ Age in years \#

Waist Circumference \#

**Body Mass Index

Self-Reflectiveness

**Self- Certainty

*BCIS Total

${ }^{*}$ RBANS Immediate Memory

RBANS Visuospatial

*RBANS Language

**RBANS Attention
Mean (SD)

45.82 (15.62)

Range: 18.06-81.12

91.13 (15.77)

$29.65(7.68)$

3.41 (5.32)

9.75 (3.39)

13.17 (4.94)

$44.58(7.87)$

$32.25(4.64)$

27.58 (5.67)

$47.39(12.91)$

\section{Mean (SD)}

49.34 (14.97)

Range: 18.25-81.12

95.37 (10.47)

31.37 (3.95)

$3.32(5.65)$

9.65 (3.42)

$12.97(5.51)$

$44.01(7.85)$

$32.27(4.12)$

27.61 (4.52)

$46.20(12.77)$ 
Table 1 Demographic, Weight and Neurocognitive Variables for Full and Included Samples (Continued)

\begin{tabular}{lll}
\hline & Full sample: $\mathbf{N = 3 1 4}$ & Included sample: $\mathbf{N}=\mathbf{1 8 4}$ \\
\hline **RBANS Delayed Recall & $47.65(7.54)$ & $47.23(7.43)$ \\
**RBANS Total & $199.35(29.11)$ & $197.11(28.44)$ \\
**Global IQ (WASI) & $67.33(15.61)$ & $68.61(13.54)$ \\
RFFT Error Ratio & $0.17(0.21)$ & $.16(0.20)$ \\
Stroop Interference & $-1.58(7.84)$ & $-2.40(8.54)$ \\
*Spatial Span Backwards & $6.07(2.18)$ & $5.92(2.14)$ \\
Digit Span Backwards & $5.29(2.21)$ & $5.25(2.34)$ \\
Total Executive Function (z-score) & $0.03(2.47)$ & $-0.04(2.48)$ \\
Total Neurocognition (z-score) & $-0.03(3.13)$ & $-0.27(3.10)$ \\
\hline
\end{tabular}

Numbers may not add up to $100 \%$ due to missing values

BCIS: Beck Cognitive Insight Scale, IQ: Intelligence Quotient, RBANS: Repeatable Battery for the Assessment of Neuropsychological Status, WASI: Wechsler Abbreviated Scale of Intelligence

\# Full and included samples differed significantly with regard to age, marital status and waist circumference

*: relationship with correct perception of body weight in included sample $-p \leq 0.10$

**: relationship with correct perception of body weight in included sample $-p \leq 0.05$

\section{Results}

A description of the full and included samples is provided in Table 1. We excluded underweight individuals (the only way they could misperceive their weight was to overestimate it) and normal weight individuals (the only way normal weight individuals could underestimate their weight was to call themselves underweight) from the analysis. We decided not to analyse individuals who overestimated their weight because of the small sample, and few normal weight individuals underestimated their weight). We also excluded morbidly and super morbidly obese individuals (i.e. class III) from further analysis, as none of these individuals perceived themselves to be underweight or of normal weight (Table 2). This left us with a sample size of $N=184$ (see Fig. 1: Flow chart of sample selection). The full and included samples differed significantly with regard to age (the included sample was older), marital status (more individuals in the included sample were never married) and waist circumference (waist sizes were larger in the included sample).

In univariate analysis the following variables were associated with incorrect perceptions of body weight $(p \leq$ 0.05): education; BMI; reported weight loss/ gain in the previous year, reported ever being obese or having a

Table 2 BMI Classification and Weight Perception Numbers

\begin{tabular}{llll}
\hline & \multicolumn{3}{l}{ Weight perception } \\
\cline { 2 - 4 } BMI Classification & Underweight & Normal Weight & Overweight \\
\hline Underweight & 4 & 6 & 0 \\
Normal & 18 & 65 & 7 \\
Overweight & 5 & 44 & 29 \\
Obese Class I & 0 & 20 & 47 \\
Obese Class II & 0 & 5 & 34 \\
Obese Class III & 0 & 0 & 30 \\
\hline
\end{tabular}

family member (blood relative) who was obese; being told to lose weight or maintain a healthy body weight by a health-care professional; self-certainty (on the BCIS); global IQ (assessed by the WASI); and the RBANS total score (memory, attention and delayed recall scores contributed to this). These variables, excluding ever being obese and global IQ, were entered into a logistic regression. For the variable 'ever obese', the same individuals who responded positively to this acknowledged being currently overweight while the variable 'global IQ' was significantly correlated with the RBANS score. We also included age, which trended towards significance $(p=$ 0.061), in the model. Cognitive variables (self-certainty; RBANS Total score) were entered in the first step, weight-related variables (BMI, reporting that one had gained weight in the previous year, that one had had blood relative who was obese, that one was told to lose weight or maintain a healthy body weight by a healthcare professional) in step two and demographic variables (age, education) in the final step.

Cognitive variables alone explained $7.1 \%$ of variation (Nagelkerke $\mathrm{R}^{2}$ ), and correctly identified $64.7 \%$ of individuals who correctly and incorrectly perceived their weight. This is $4.9 \%$ higher than when the constant alone was included in the model. When weight-related variables were added to the model, $50.5 \%$ of variation was explained and $78.8 \%$ of individuals who correctly and incorrectly perceived their weight were correctly identified. The final logistic regression model, which include the demographic variables and, explained $52.3 \%$ of variation in accurate perception of body weight, correctly classified $79.3 \%$ of individuals who correctly and incorrectly perceiving their weight, and was significant $(X 2 \quad(10, N=184)=90.137, p \leq 0.01)$. Table 3 provides a summary of each variable in the equation whilst controlling for the other variables. 


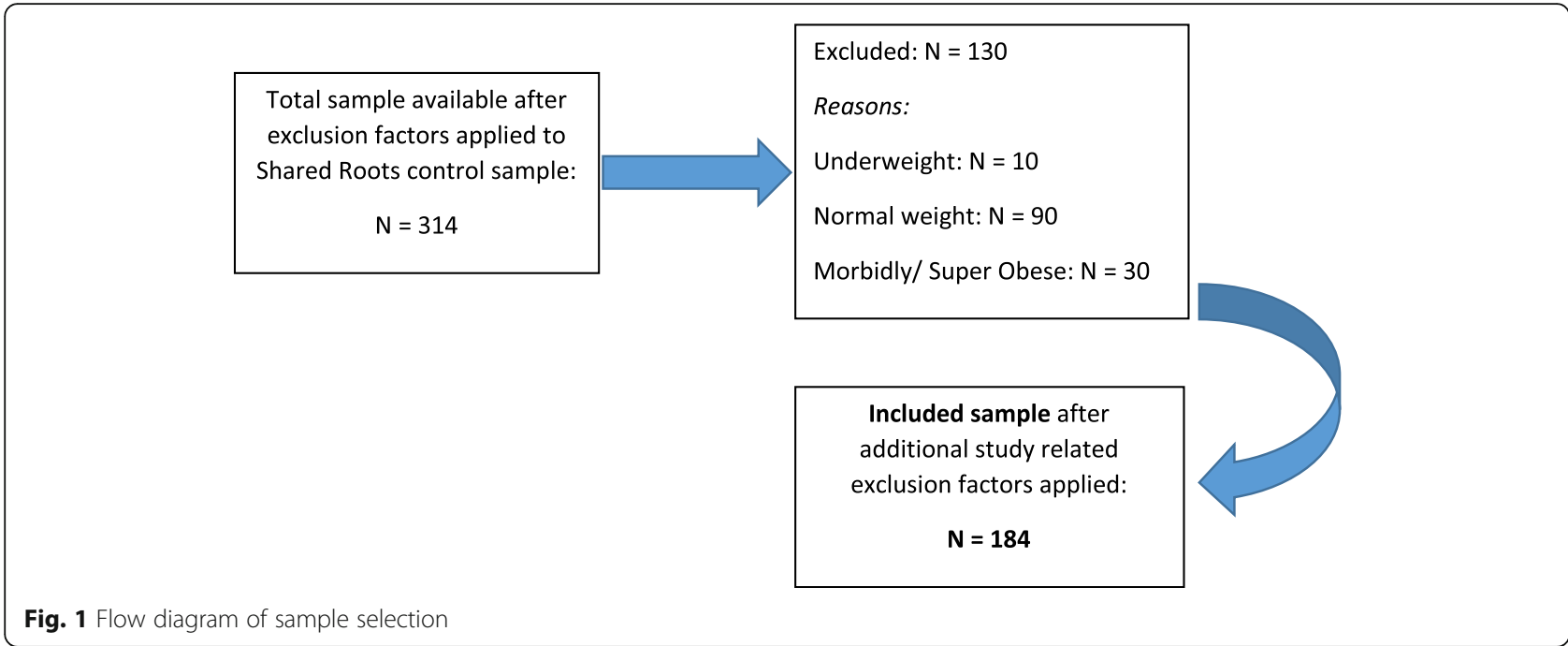

The RBANS total score, having overweight blood relatives, age and education were not significant when other variables in the equation were controlled for. Self-certainty, BMI, reported weight change and having being told to lose/ maintain a healthy weight by a health care professional and were significant in the final equation. Individuals with greater self-certainty and those with lower BMI were less likely to perceive their weight correctly; while those who reported that they had gained weight in the previous year or were told by a health-care professional to lose or maintain a healthy weight were more likely to perceive their weight correctly. For example, reporting that one was told to lose or maintain a healthy weight by a healthcare professional resulted in an increase of 0.985 in the log-odds of the dependent variable (correct perception of weight), holding all other independent variables constant.

\section{Discussion}

This is the first study, to our knowledge, to demonstrate a strong association between cognitive insight, rather

Table 3 Hierarchical Regression of Factors Associated with Perception of Body Weight

\begin{tabular}{|c|c|c|c|c|c|c|c|c|}
\hline \multirow[t]{2}{*}{ Predictor } & \multirow{2}{*}{$\begin{array}{l}\text { B (coefficient } \\
\text { for the constant) }\end{array}$} & \multirow[t]{2}{*}{ SE $\beta$} & \multirow{2}{*}{$\begin{array}{l}\text { Wald's } \\
X^{2}\end{array}$} & \multirow[t]{2}{*}{ df } & \multirow{2}{*}{$\begin{array}{l}p \\
\text { (Significance) }\end{array}$} & \multirow{2}{*}{$\begin{array}{l}e^{\beta} \text { (Odds } \\
\text { ratio) }\end{array}$} & \multicolumn{2}{|c|}{ 95\% C.I.for EXP(B) } \\
\hline & & & & & & & Lower & Upper \\
\hline RBANS: total score & -0.015 & 0.010 & 02.110 & 1 & $>0.05$ & 0.985 & 0.966 & 1.005 \\
\hline BCIS: self-certainty total score & 0.163 & 0.062 & 6.944 & 1 & $\leq 0.01^{* *}$ & 1.177 & 1.043 & 1.328 \\
\hline BMl & -0.366 & 0.068 & 29.172 & 1 & $\leq 0.001^{* *}$ & 0.694 & 0.607 & 0.792 \\
\hline Weight changes & & & 14.725 & 2 & $\leq 0.001^{* *}$ & & & \\
\hline Weight changes (1) & 1.205 & 0.684 & 3.102 & 1 & $>0.05$ & 3.338 & 0.873 & 12.761 \\
\hline Weight changes (2) & -1.633 & 0.534 & 9.360 & 1 & $\leq 0.01^{* *}$ & 0.195 & 0.069 & 0.556 \\
\hline Overweight blood relatives & -0.482 & 0.423 & 1.299 & 1 & $>0.05$ & 0.617 & 0.269 & 1.415 \\
\hline Maintain a healthy body weight or lose weight & 0.985 & 0.460 & 4.591 & 1 & $\leq 0.05^{*}$ & 2.678 & 1.088 & 6.591 \\
\hline Age & 0.006 & 0.016 & 0.124 & 1 & $>0.05$ & 1.006 & 0.974 & 1.038 \\
\hline HLOE & & & 3.552 & 2 & $>0.05$ & & & \\
\hline HLOE (1) & -0.874 & 0.684 & 1.630 & 1 & $>0.05$ & 0.417 & 0.109 & 1.596 \\
\hline HLOE (2) & -1.517 & 0.816 & 3.455 & 1 & $>0.05$ & 0.219 & 0.044 & 1.086 \\
\hline Constant & 12.747 & 3.385 & 14.179 & 1 & $\leq 0.001^{* *}$ & $343,400.256$ & & \\
\hline
\end{tabular}

BCIS: Beck Cognitive Insight Scale, BMI: Body mass index, HLOE: Highest level of education; RBANS: Repeatable Battery for the Assessment of Neuropsychological Status

HLOE Reference category $=0$ = Primary school or less, $1=$ Some secondary school, $2=$ Completed secondary school

Weight changes: Reference category $=0=$ No significant weight changes, $1=$ Weight decreased, $2=$ Weight increased

*: relationship with correct perception of body weight $-p \leq 0.05$

**: relationship with correct perception of body weight $-p \leq 0.01$

Note: Supplementary Table 1 compares these results to regression results when those who misperceived their weight to be higher were included in the analysis 
than cognitive function, on PBW. Over one third of individuals in the study misperceived their weight, with the majority underestimating their weight. Weight underestimation was also associated with greater self-certainty. The prevalence of misperception of body weight in this sample is lower than other studies conducted in subSaharan Africa [7, 42, 43], as well as lower than that found in other LMICs [44, 45]. It has been suggested that cultural preferences for obesity, and limited opportunities to measure actual weight may contribute to misperceptions about body weight [42]. Given that recruitment was targeted at individuals at risk for cardiovascular disease, many individuals in our study might have already been aware of their weight status.

We aimed to determine whether better cognitive functioning and better cognitive insight were associated with PBW. In univariate analysis, those with a higher global IQ and neurocognition score (as assessed on the RBANS) were more likely to perceive their weight correctly. This relationship did not hold once other variables were accounted for. Despite the association between obesity and impaired cognitive performance $[46,47]$, this relationship does not seem to extend to correct perception of body weight.

In both univariate and multivariate analyses, those with high self-certainty were more likely to underestimate their weight. Confidence and satisfaction with oneself is likely to allow individuals to view themselves in a more positive light as demonstrated by the relationship between self-certainty and self-esteem [48]. Given that perceptions of obesity and overweight may have cultural determinants this may reflect a cultural belief that overweight/ obesity is 'normal' and desirable [49]. For instance, a qualitative study conducted in a black South African population found that most of the obese and overweight women perceived themselves to weigh less than they did, and expressed satisfaction with their body sizes [50]. Additionally, both overweight and normal weight women perceived large body sizes as attractive and 'normal' [50]. As such, these individuals may be less responsive to other external cues (e.g. persuasion,) of their current weight status, and may require more direct feedback.

We also aimed to identify weight-related and sociodemographic factors associated with correct perception of body weight. In univariate analysis the presence of an obese family member and higher level of education were significantly associated with correct $\mathrm{PBW}$, while age trended towards significance. These variables were no longer significant when other variables were accounted for. This is in contrast to other studies, including those in LMIC that have found demographic factors such as SES, age and gender to be related to PBW [42, 43, 51]. BMI, reporting that one had gained weight in the previous year, ever being obese or being previously told to lose weight or maintain a healthy body weight by a healthcare professional remained significant in the multivariate model.

Those with a lower BMI were more likely to underestimate their weight. Considering that this sample comprised only overweight and obese participants, this means the closer one is to a normal BMI, the more likely they are to think they are normal - as weight increases the less likely participants are to think they are normal and/or weight gain becomes harder to deny. A Norwegian study of overweight individuals had similar resultsfinding that a higher BMI was protective against weight underestimation [15]. However, as our categories were limited to three groups (participants could only select whether they perceived themselves to be underweight, normal weight or overweight) this decreased our sensitivity to pick up whether individuals with very high BMIs were also underestimating their weight - these individuals, for instance, might think they are overweight when they are in fact obese.

Those who reported that they had gained weight were less likely to underestimate their weight. This may relate to perceptions of oneself- if in denial of being overweight an individual may also be in denial of having gained weight. Alternatively, it may be that, having gained weight, these individuals are more aware of their current weight status. A study that assessed parental perception of child overweight two years later, for example, found that perception of overweight seemed mainly to reflect an awareness of an already rising trajectory [52].

Having a healthcare worker tell one to lose weight/ maintain a healthy body weight decreased the likelihood of individuals underestimating their weight, when other factors were controlled for. This stands to reason, given that this would have raised participants awareness of their body weight, and aligns with other research [53]. This could also suggest that the advice of healthcare professionals is more effective than other forms of social influence and highlights the relevance of physician informed strategies in reducing weight-related morbidity. Nonetheless, accurate perception of weight does not necessarily relate to changes in behaviour [52, 54].

Some limitations should be considered. First, in examining the relationship between BMI classification and perception of weight, categories of underweight, overweight and normal weight may have been too restrictive to determine the accuracy of weight perception in morbidly and super morbidly obese individuals, as their weight was too far out of the normal range. We therefore excluded these individuals from our analysis. Second, we further excluded individuals who overestimated 
their weight as different factors have been found to be associated with overestimating than underestimating weight [55], and there were too few individuals who overestimated their weight to analyse this group separately. Third, normal weight individuals were also excluded as the only way they could misperceive their weight was to say they were underweight, and very few participants did so. It is also likely that different factors come into play here. Fourth, this was a cross-sectional study limiting inferences about directionality. Longitudinal studies will allow more accurate determination of the association between weight perception and later physical and mental health behaviours and health outcomes. A review of the association between obesity and cognitive function, for example, found longitudinal evidence that lower childhood intelligence leads to obesity and weight gain in adulthood, with no credible evidence to the contrary [56]. Fifth, the BCIS is not the ideal measure to evaluate insight in non-psychotic patients. Future studies should preferably use an obesity related insight measure such as The Obesity Awareness and Insight Scale [57]. Finally, as participants were recruited using purposive sampling they may not represent a random population and generalisability may be limited.

\section{Conclusion}

Despite these limitations, these findings suggest that some aspects of cognitive insight (self-certainty) but not cognitive functioning are associated with perception of body weight in this sample. Furthermore, weight-related variables, such as BMI, reporting that one had gained weight in the previous year, ever being obese, or being previously told to lose weight or maintain a healthy body weight by a healthcare professional, were associated with perceptions of body weight in this sample, while demographic variables were not. Understanding factors that contribute to the correct perception of one's weight is important in identifying appropriate public health interventions such as Cardiovascular Disease prevention programs. Clinically, our results may indicate that healthcare providers need to be more vigilant in identifying those who are overweight and counsel these individuals regarding health and lifestyle modification, for example. Given that misperception of one's weight (under- and over-) can influence physical and mental health, such interventions may address the burden of associated non-communicable diseases in this population. Even so, weight underestimation may also be protective of one's mental health. As such, the potential negative effects of correcting weight misperceptions need to be considered when implementing lifestyle and behavioural interventions.

\section{Abbreviations}

BCIS: Beck Cognitive Insight Scale; BMI: Body Mass Index; cm: Centimetres; IQ : Intelligence Quotient; kg : Kilograms; LMIC : Low- and middle-income countries; MINI: MINI International Neuropsychiatric Interview; PBW : Perceived body weight; RBANS: Repeatable Battery for the Assessment of Neuropsychological Status; SES: Socio-economic status; WASI : Wechsler Abbreviated Scale of Intelligence

\section{Supplementary Information}

The online version contains supplementary material available at https://doi. org/10.1186/s12889-021-10559-5.

Additional file 1: Supplementary Table: Hierarchical Regression of Factors Associated with Perception of Body Weight in (A) 'Included' sample and (B) 'Included' sample and those who misperceived their weight to be higher.

\section{Acknowledgements}

None to declare.

\section{Authors' contributions}

CRediT authorship contribution statement: Sharain Suliman:

Conceptualisation, Data curation, Formal analysis, Investigation, Methodology, Validation, Visualisation, Writing - original draft, Writing review \& editing. Leigh Luella van den Heuvel: Conceptualization, Data curation, Formal analysis, Investigation, Methodology, Project administration, Visualization, Writing - review \& editing. Sanja Kilian: Investigation, Writing review \& editing. Erine Bröcker: Investigation, Writing - review \& editing. Laila Asmal: Investigation, Writing - review \& editing. Robin Emsley: Funding acquisition, Methodology, Project administration, Resources; Writing - review \& editing. Soraya Seedat: Conceptualization, Funding acquisition,

Methodology, Project administration, Resources, Supervision, Writing - review \& editing. The authors read and approved the final manuscript.

\section{Funding}

Research reported in this publication was supported by the South African Medical Research Council for the "Shared Roots" Flagship Project, Grant no. MRC-RFA-IFSP-01-2013/SHARED ROOTS" through funding received from the South African National Treasury under its Economic Competitiveness and Support Package.

Sharain Suliman received post-doctoral support from the South African Research Chairs Initiative in PTSD funded by the Department of Science and Technology and the National Research Foundation and a SAMRC Self- Initiated Research Grant.

Leigh van den Heuvel received funding from y the South African Medical Research Council through its Division of Research Capacity Development under the SAMRC CLINICIAN RESEARCHER (M.D PHD) SCHOLARSHIP PROGRAMME from funding received from the South African National Treasury.

Erine Bröcker received funding support from the South African Medical Research Council through its Division of Research Capacity Development under the SAMRC Bonga Mayosi national health scholars programme of the South African Nation Treasury.

Soraya Seedat is supported by the South African Research Chairs Initiative in PTSD funded by the Department of Science and Technology and the National Research Foundation and the South African Medical Research Council Extramural Unit on the Genomics of Brain Disorders.

Funders have played no role in the study design, data collection, analysis, and interpretation and in writing the manuscript. Its' contents are solely the responsibility of the authors and do not necessarily represent the official views of the South African Medical Research Council.

Availability of data and materials

Data will be made available upon reasonable request. Requests may be sent to Sharain Suliman: sharain@sun.ac.za. 


\section{Declarations}

\section{Ethics approval and consent to participate}

The study was approved by the Stellenbosch University Faculty of Medicine and Health Sciences Human Research Ethics Committee (reference number: N13/08/115), conducted in accordance with the Declaration of Helsinki, and all participants signed informed consent.

\section{Consent for publication}

Not Applicable.

\section{Competing interests}

None to declare.

Received: 24 April 2020 Accepted: 4 March 2021

Published online: 19 March 2021

\section{References}

1. OECD/EU. 98 4. OVERWEIGHT AND OBESITY AMONG ADULTS. 2016. http:// www.oecd-ilibrary.org/docserver/download/8116231ec026.pdf?expires=14 95783749\&id=id\&accname $=$ guest\&checksum=5450F8E9D21206D8E73 C60991D3DFOCB. Accessed 26 May 2017.

2. WHO. Obesity and overweight. World Health Organization; 2016. http:// www.who.int/mediacentre/factsheets/fs311/en/. Accessed 26 May 2017.

3. WHO | Double burden of malnutrition. WHO. 2017. https://www.who.int/ nutrition/double-burden-malnutrition/en/. Accessed 27 Aug 2019.

4. Bhurtun DD, Jeewon R. Body Weight Perception and Weight Control Practices among Teenagers. ISRN Nutr. 2013; 1-6. doi:https://doi.org/10.54 02/2013/395125.

5. Cheung PC, LS P, St I, Bibby LH. A study on body weight perception and weight control behaviours among adolescents in Hong Kong. Hong Kong Med J 2007. 2007;13:16-21. http://www.hkmj.org/system/files/hkm0702p16 pdf. Accessed 24 May 2017.

6. Tremblay L, Limbos M. Body image disturbance and psychopathology in children: research Evi-dence and implications for prevention and treatment. Curr Psychiatr Rev. 2009;5:62-72.

7. Mchiza ZJ, Whadiah P, Mokhantso M, Ronel S, Kupamupindi T, Labadarios D. Body image and weight control in south Africans 15 years or older: SANH ANES-1. BMC Public Health. 2015:15:1-11.

8. Roberts RE, Duong HT. Perceived weight, not obesity, increases risk for major depression among adolescents. J Psychiatr Res. 2013;47:1110-7. https://doi.org/10.1016/j.jpsychires.2013.03.019.

9. Shin A, Nam CM. Weight perception and its association with sociodemographic and health-related factors among Korean adolescents. BMC Public Health. 2015;15:1292. https://doi.org/10.1186/s12889-015-2624-2.

10. Atlantis E, Ball K. Association between weight perception and psychological distress. Int J Obes. 2008;32:715-21. https://doi.org/10.1038/sj.jjo.0803762.

11. Lee K-M, Seo M-S, Shim J-Y, Lee Y-J. Body weight status misperception and its association with weight control behaviours, depressive mood and psychological distress in nulliparous normal-weight young women. Ann Hum Biol. 2015;42:528-32. https://doi.org/10.3109/03014460.2015.1006139.

12. Lam CK, Huang X, Chiu WCK. Mind over body? The combined effect of objective body weight, perceived body weight, and gender on illnessrelated absenteeism. Sex Roles. 2010;63:277-89. https://doi.org/10.1007/s111 99-010-9779-1.

13. Al Mamun A, Cramb S, McDermott BM, O'Callaghan M, Najman JM, Williams GM. Adolescents' perceived weight associated with depression in young adulthood: a longitudinal study**. Obesity. 2007;15:3097-105. https://doi. org/10.1038/oby.2007.369.

14. Thurston IB, Sonneville KR, Milliren CE, Kamody RC, Gooding HC, Richmond TK. Cross-sectional and prospective examination of weight misperception and depressive symptoms among youth with overweight and obesity. Prev Sci. 2017;18:152-63. https://doi.org/10.1007/s11121-016-0714-8.

15. Kvaløy K, Melhus M, Silviken A, Broderstad AR. Weight underestimation linked to anxiety and depression in a cross-sectional study of overweight individuals in a Sami and non-Sami Norwegian population: the SAMINOR study. BMJ Open. 2019;9:e031810. https:/doi.org/10.1136/bmjopen-2019-031810.

16. Unger ES, Kawachi I, Milliren CE, Sonneville KR, Thurston IB, Gooding HC, et al. Protective misperception? Prospective study of weight self-perception and blood pressure in adolescents with overweight and obesity. J Adolesc Health. 2017;60:680-7.
17. Duncan DT, Wolin KY, Scharoun-Lee M, Ding EL, Warner ET, Bennett GG Does perception equal reality? Weight misperception in relation to weightrelated attitudes and behaviors among overweight and obese US adults. Int J Behav Nutr Phys Act. 2011;8. https://doi.org/10.1186/1479-5868-8-20.

18. Gregory CO, Blanck HM, Gillespie C, Michele Maynard L, Serdula MK. Health perceptions and demographic characteristics associated with underassessment of body weight. Obesity. 2008;16:979-86. https://doi.org/1 0.1038/oby.2008.22.

19. Kim KH. Cheon. Religion, weight perception, and weight control behavior. Eat Behav. 2007:8:121-31.

20. Al Sabbah H, Vereecken CA, Elgar FJ, Nansel T, Aasvee K, Abdeen Z, et al. Body weight dissatisfaction and communication with parents among adolescents in 24 countries: International cross-sectional survey. BMC Public Health. 2009;9:52. https://doi.org/10.1186/1471-2458-9-52.

21. Akgöz A, Gözüm S, llgaz A. A comparative study on perception of body weight of women from different socioeconomic levels. Health Care Women Int. 2017:9332:1-12. https://doi.org/10.1080/07399332.2017.1325487.

22. Yang Y, Shields GS, Guo C, Liu Y. Executive function performance in obesity and overweight individuals: a meta-analysis and review. Neurosci Biobehav Rev. 2018;84:225-44

23. Forcano L, Mata F, de la Torre R, Verdejo-Garcia A. Cognitive and neuromodulation strategies for unhealthy eating and obesity: systematic review and discussion of neurocognitive mechanisms. Neurosci Biobehav Rev. 2018;87:161-91

24. Fitzpatrick S, Gilbert S, Serpell L. Systematic review: are overweight and obese individuals impaired on behavioural tasks of executive functioning? Neuropsychol Rev. 2013;23:138-56.

25. Liang J, Matheson BE, Kaye WH, Boutelle KN. Neurocognitive correlates of obesity and obesity-related behaviors in children and adolescents. Int J Obes. 2014;38:494-506.

26. Docteur A, Urdapilleta I, Rico DL. The role of cognitive factors in body-size perception and recall-size estimation in normal-weight women. Rev Eur Psychol Appl. 2012;62:129-35.

27. Beck AT, Baruch E, Balter JM, Steer RA, Warman DM. A new instrument for measuring insight: the Beck cognitive insight scale. Schizophr Res. 2004;68: 319-29. https://doi.org/10.1016/S0920-9964(03)00189-0.

28. Nair A, Palmer EC, Aleman A, David AS. Relationship between cognition, clinical and cognitive insight in psychotic disorders: a review and meta-analysis. Schizophr Res. 2014;152:191-200. https://doi.org/10.1016/j.schres.2013.11.033.

29. Ohmuro N, Katsura M, Obara C, Kikuchi T, Hamaie Y, Sakuma A, et al. The relationship between cognitive insight and cognitive performance among individuals with at-risk mental state for developing psychosis. 2017. https:// doi.org/10.1016/j.schres.2017.04.031

30. Lepage M, Buchy L, Bodnar M, Bertrand MC, Joober R, Malla A. Cognitive insight and verbal memory in first episode of psychosis. Eur Psychiatry. 2008;23:368-74. https://doi.org/10.1016/j.eurpsy.2008.02.003.

31. Cooke MA, Peters ER, Fannon D, Aasen I, Kuipers E, Kumari V. Cognitive insight in psychosis: the relationship between self-certainty and selfreflection dimensions and neuropsychological measures. Psychiatry Res. 2010;178:284-9. https://doi.org/10.1016/j.psychres.2009.05.009.

32. Ferrett HL, Carey PD, Thomas KGF, Tapert SF, Fein G. Neuropsychological performance of south African treatment-naïve adolescents with alcohol dependence. Drug Alcohol Depend. 2010;110:8-14. https://doi.org/10.1016/ j.drugalcdep.2010.01.019.

33. Transperfect. RBANS Translation Process.

34. Sheehan DV, Lecrubier $Y$, Sheehan $K H$, Amorim P, Janavs J, Weiller $E$, et al. The Mini-International Neuropsychiatric Interview (M.I.I.I.): the development and validation of a structured diagnostic psychiatric interview for DSM-IV and ICD-10. J Clin Psychiatry. 1998:59 Suppl 20:22-33 quiz 34-57. http:// www.ncbi.nlm.nih.gov/pubmed/9881538. Accessed 9 Mar 2018.

35. World Health Organization. Body mass index - BMI. 2019. http://www.euro. who.int/en/health-topics/disease-prevention/nutrition/a-healthy-lifestyle/ body-mass-index-bmi. Accessed 28 Aug 2019

36. World Health Organization. WHO STEPS Surveillance Manual: World Health Organization; 2017.

37. Psychcorp. Wechsler Abbreviated Scale of Intelligence: Manual. San Antonio, Texas: Harcourt Assessment; 1999.

38. Randolph C, Tierney MC, Mohr E, Chase TN. The Repeatable Battery for the Assessment of Neuropsychological Status (RBANS): Preliminary Clinical Validity. J Clin Exp Neuropsychol. 1998;20:310-9. https://doi.org/10.1076/ jcen.20.3.310.823. 
39. Ruff RM, Light RH, Evans RW. The ruff figural fluency test: a normative study with adults. Dev Neuropsychol. 1987;3:37-51. https://doi.org/10.1080/ 87565648709540362.

40. Golden CJ, Freshwater SM. The Stroop color and word test: a manual for clinical and experimental uses. Chicago, IL: Stoelting; 2002.

41. Wechsler D. Wechsler memory scale - third edition: administration and scoring manual. San Antonio, TX: The Psychological Corporation; 1997.

42. Tateyama Y, Techasrivichien T, Musumari PM, Suguimoto SP, Zulu R, Macwan'gi M, et al. Obesity matters but is not perceived: a cross-sectional study on cardiovascular disease risk factors among a population-based probability sample in rural Zambia. PLoS One. 2018;13:e0208176. https://doi. org/10.1371/journal.pone.0208176.

43. Akindele MO, Phillips J, lgumbor E, Useh U. Body weight misperception and dissatisfaction among overweight and obese adult Nigerians. JMIR public Heal Surveill. 2017:3:e56. https://doi.org/10.2196/publichealth.7047.

44. Bhanji S, Khan Khuwaja A, Siddiqui F, Azam I, Kazmi K. Underestimation of weight and its associated factors among overweight and obese adults in Pakistan: a cross sectional study. BMC Public Health. 2011;11. https://doi. org/10.1186/1471-2458-11-363.

45. Jayawardena R, Byrne NM, Soares MJ, Katulanda P, Hills AP. Body weight perception and weight loss practices among Sri Lankan adults. Obes Res Clin Pract. 2014;8:e192-200. https://doi.org/10.1016/J.ORCP.2 013.05.003.

46. Dye L, Boyle NB, Champ C, Lawton C. The relationship between obesity and cognitive health and decline. Proc Nutr Soc. 2017;76:443-54. https://doi. org/10.1017/S0029665117002014.

47. Wang C, Chan JSY, Ren L, Yan JH. Obesity reduces cognitive and motor functions across the lifespan. Neural Plast. 2016. https://doi.org/10.1155/201 6/2473081.

48. Wright R. Self-certainty and self-esteem. In: Extending Self-Esteem Theory and Research: Cambridge University Press; 2009. p. 101-34. https://doi.org/1 0.1017/cbo9780511527739.006.

49. Wright EJ, Whitehead TL. Perceptions of body size and obesity: a selected review of the literature. J Community Health. 1987;12:117-29.

50. Okop K, Mukumbang FC, Mathole T, Levitt N, Puoane T. Perceptions of body size, obesity threat and the willingness to lose weight among black south African adults: a qualitative study. BMC Public Health. 2016;16.

51. Ben Ayed H, Yaich S, Ben Jemaa M, Ben Hmida M, Trigui M, Jedidi J, et al. What are the correlates of body image distortion and dissatisfaction among school-adolescents? Int J Adolesc Med Health. 2019;0. https://doi.org/10.151 5/ijamh-2018-0279.

52. Wake M, Kerr JA, Jansen PW. Child BMI over time and parent-perceived overweight. Pediatrics. 2018;142(6):e20173985.

53. Harris CL, Strayhorn G, Moore S, Goldman B, Martin MY. Perceived physician-informed weight status predicts accurate weight self-perception and weight self-regulation in low-income, African American women. J Health Care Poor Underserved. 2016;27:1441-63. https://doi.org/10.1353/ hpu.2016.0140.

54. Feng X, Wilson A. Does dissatisfaction with, or accurate perception of overweight status help people reduce weight? Longitudinal study of Australian adults. BMC Public Health. 2019;19:619. https://doi.org/10.1186/ s12889-019-6938-3.

55. Brug J, Wammes B, Kremers S, Giskes K, Oenema A. Underestimation and overestimation of personal weight status: associations with sociodemographic characteristics and weight maintenance intentions. J Hum Nutr Diet. 2006;19:253-62. https://doi.org/10.1111/j.1365-277X.2006.00707.x.

56. Kanazawa S. Intelligence and obesity. Curr Opin Endocrinol Diabetes Obes. 2014;21:339-44. https://doi.org/10.1097/MED.00000000000000091.

57. Gerretsen P, Kim J, Shah P, Quilty L, Balakumar T, Caravaggio F, et al. OASIS: the obesity awareness and insight scale. Obes Med. 2018;9:38-44.

\section{Publisher's Note}

Springer Nature remains neutral with regard to jurisdictional claims in published maps and institutional affiliations.

Ready to submit your research? Choose BMC and benefit from:

- fast, convenient online submission

- thorough peer review by experienced researchers in your field

- rapid publication on acceptance

- support for research data, including large and complex data types

- gold Open Access which fosters wider collaboration and increased citations

- maximum visibility for your research: over $100 \mathrm{M}$ website views per year

At BMC, research is always in progress.

Learn more biomedcentral.com/submissions 